\title{
Article
}

\section{Room Temperature Reactivity Of Silicon Nanocrystals With Solvents: The Case Of Ketone And Hydrogen Production From Secondary Alcohols: Catalysis?}

Jehad El-Demellawi, Christopher R. Holt, Edy AbouHamad, Zeyad A. Al-talla, Youssef Saih, and Sahraoui Chaieb

ACS Appl. Mater. Interfaces, Just Accepted Manuscript • DOI: 10.1021/acsami.5b01231 • Publication Date (Web): 29 May 2015

Downloaded from http://pubs.acs.org on May 31, 2015

\section{Just Accepted}

"Just Accepted" manuscripts have been peer-reviewed and accepted for publication. They are posted online prior to technical editing, formatting for publication and author proofing. The American Chemical Society provides "Just Accepted" as a free service to the research community to expedite the dissemination of scientific material as soon as possible after acceptance. "Just Accepted" manuscripts appear in full in PDF format accompanied by an HTML abstract. "Just Accepted" manuscripts have been fully peer reviewed, but should not be considered the official version of record. They are accessible to all readers and citable by the Digital Object Identifier (DOI®). "Just Accepted" is an optional service offered to authors. Therefore, the "Just Accepted" Web site may not include all articles that will be published in the journal. After a manuscript is technically edited and formatted, it will be removed from the "Just Accepted" Web site and published as an ASAP article. Note that technical editing may introduce minor changes to the manuscript text and/or graphics which could affect content, and all legal disclaimers and ethical guidelines that apply to the journal pertain. ACS cannot be held responsible for errors or consequences arising from the use of information contained in these "Just Accepted" manuscripts. 


\title{
Room Temperature Reactivity Of Silicon Nanocrys-
}

\section{tals With Solvents: The Case Of Ketone And Hydro- gen Production From Secondary Alcohol: Catalysis?}

\author{
Jehad K. El-Demellawi, ${ }^{1}$ Christopher R. Holt, ${ }^{1}$ Edy Abou-Hamad, ${ }^{2}$ Zeyad A. Al-Talla, ${ }^{3}$ Youssef \\ Saih, $^{2}$ and Sahraoui Chaieb ${ }^{1^{*}}$ \\ ${ }^{1}$ Physical Sciences and Engineering Division, King Abdullah University of Science and Technol- \\ ogy, Thuwal 23955-6900, Saudi Arabia \\ ${ }^{2}$ KAUST Catalysis Center, King Abdullah University of Science and Technology, Thuwal 23955- \\ 6900, Saudi Arabia \\ ${ }^{3}$ Analytical Core Laboratory, King Abdullah University of Science and Technology, Thuwal \\ 23955-6900, Saudi Arabia
}

KEYWORDS: Silicon Nanocrystals; Heterogenous Catalysis; NMR; Mass Spectroscopy; Hydrogen Production; Alcohol Dehydrogenation 


\begin{abstract}
Although silicon nanoparticles dispersed in liquids are used in various applications ranging from bio-labeling to hydrogen production, their reactivities with their solvents and their catalytic properties remain still unexplored. Here, we discovered that, because of their surface structures and mechanical strain, silicon nanoparticles react strongly with their solvents and may act as catalysts for the dehydrogenation, at room temperature, of secondary alcohols (e.g. isopropanol) into ketones and hydrogen. This catalytic reaction was monitored by gas chromatography, $\mathrm{pH}$ measurements, mass spectroscopy and solid-state NMR. This discovery provides new understanding of the role played by silicon nanoparticles, and nanosilicon in general, in their reactivity in solvents in general as well as being candidates in catalysis.
\end{abstract}

\title{
INTRODUCTION
}

Nanoparticles are unique for two reasons: A large proportion of their atoms lie on the surface and these atoms do not necessarily order themselves in a similar fashion as those in bulk materials do. ${ }^{1,2}$ Because of their high surface-to-volume ratio, nanoparticles are used in a gamut of applications such as chemical sensors, ${ }^{3}$ optical devices ${ }^{4}$ in which size is important, ${ }^{5}$ energy harvesting $^{6}$ as well as flexible devices ${ }^{7}$ and many more. One of their most extensive usages is in chemical synthesis and in particular their catalytic properties. Their sizes and shapes are indeed important to optimum catalytic activity. ${ }^{8,9-11}$ The size of nanoparticles can be finely tuned and their surface can be modified at the atomic level, which makes them ideal in heterogeneous catalysis. Apart from zeolites, ${ }^{12}$ mostly zerovalent metallic nanoparticles are used in heterogeneous catalysis. ${ }^{13-19}$ Whereas HF-treated silicon nanowires were used as a photocatalyst in the reduction of Rhodamine $\mathrm{B},{ }^{20}$ or to catalyze p-nitrophenol reduction in the presence of a reducing agent $\mathrm{NaBH}_{4},{ }^{21}$ or playing the role of an enzyme such as a reductase during the reduction of MTT used 
in cells viability studies ${ }^{22}$ as well as used to enhance the photo-oxidation of water when combined with $\mathrm{TiO}_{2}{ }^{23}$ silicon nanoparticles on the other hand, are still mostly used for sensing and photonic applications. To our best knowledge, there has been no report as yet on the use silicon nanoparticles (SiNPs) in any catalytic reaction, although it is known that silicon react strongly with oxygen ( $\Delta \mathrm{H}$ of Si-O bond formation is $452 \mathrm{~kJ} / \mathrm{mol}.) .{ }^{24}$ Reactivity in general and Catalysis in particular is essentially a surface property. In order to detect any catalytic reaction on silicon one must be able to synthetize mono-dispersed nanoparticles because catalysis requires high surface area materials of very small size. Evidently this is a simplification of the catalytic phenomenon, which is dependent not only on the dispersion but also on specific activity of the exposed crystalline planes and on morphology parameters (i.e. structures with corners versus spheres). For example real breakthrough for this particle size-effect has been made by Haruta in the case of gold for which dramatic increase of catalytic properties has been detected for small Au nanoparticles (NPs). ${ }^{25}$

We have been using an inexpensive method, through colloidal etching, ${ }^{5}$ to fabricate silicon nanoparticles whose size is around $2.5 \mathrm{~nm}$ (Figure 1 and description in supporting information). It was therefore interesting to explore the possible catalytic properties of these nanoparticles. The dehydrogenation of alcohols to aldehydes or ketones is a well-known industrial process, and these reactions are primarily carried out on copper or palladium catalysts at high temperatures because of their high selectivity to the dehydrogenation product. The principal catalyst that has been used in these reactions is copper chromite; ${ }^{26,27}$ however, new EPA restrictions now prohibit the disposal of chromite in landfills. The production of acetone for example is also usually performed at high temperature, which is not cost effective when done at large scales. Thus, there is an incentive to develop new replacement catalysts, which contain no heavy metals and which could be used at standards conditions of temperature and pressure. The simplest model 
reaction chosen was the dehydrogenation of secondary alcohols (such as Isopropanol) to ketones (Acetone) in water. (One of the reasons that spurred this interest is that silicon nanoparticles are often stored for long periods of time in alcohols.) We want to disclose here that, to our surprise, such reaction can now occur at room temperature and low pressure. Although such reaction is known but it usually occurs at relatively high temperature with the usage of often-toxic catalysts. $^{28}$

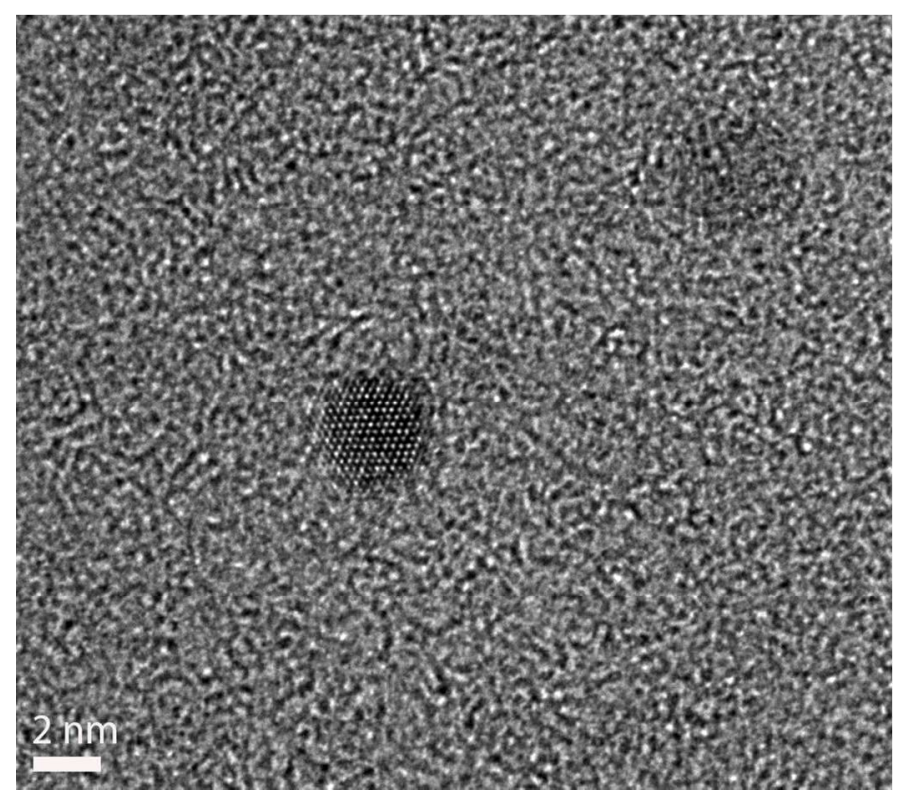

Figure 1. High Resolution TEM of a $2.5 \mathrm{~nm}$ SiNPs in the [111] directions.

\section{EXPERIMENTAL SECTION}

Colloidal silicon nanoparticles (SiNPs) were fabricated through electrolytic stain etching and electro-etching of p-type single crystal (100-oriented) boron doped silicon wafers (Addison Electronics). ${ }^{5}$ The silicon wafers were cleaved into 2.5 x $4.5 \mathrm{~cm}$ strips, and immersed in 50:1 solution of deionized water and hydrofluoric acid (49\%, Fluka) for 3-4 minutes for native oxide removal. The silicon was then laterally anodized while being dipped into a $3: 2: 1$ solution of hydrogen peroxide, $\mathrm{H}_{2} \mathrm{O}_{2},(30 \%$ by volume), methanol ( $\geq 98 \%$ purity), and $\mathrm{HF}$ (49\%, Fluka). A 
current of 50-60 mA was supplied to each strip by a current supply through a platinum wire cathode. The strips were lowered into the etchant at a rate of $4 \mathrm{~mm} / \mathrm{hr}$ and etched for 1 hour. To prevent excess heating due to the electric current, a heat exchanger was mounted underneath the etching bath. Temperatures in the bath were monitored by a thermocouple imbedded in the bath wall and were kept below $25^{\circ} \mathrm{C}$ while etching. Following etching, wafer strips were cleaned through brief dipping in deionized water followed by rinsing in absolute ethanol and then dried under a $\mathrm{N}_{2}$ stream. The nanoparticles were dispersed into an organic solvent by sonicating the strips for 15 minutes. Unlike Belomoin et al., ${ }^{5}$ no post-processing steps were used to break down larger structures and recover larger crystals. We were very careful to perform all experiments in controlled atmosphere. Hydrogen passivation is demonstrated in FTIR (Figure S1) and NMR spectra as seen below in the text.

High resolution transmission electron microscopy (HRTEM) images were recorded using a FEI Krios CT-TEM at an operating voltage of $120 \mathrm{kV}$. Fluorescence spectra were determined using a Horiba Fluoromax-4 spectrofluorometer. Absorbance measurements were carried out using a Genysis 10S UV-Vis Spectrometer (Thermo Scientific). FT-IR spectra were recorded using a Thermo Nicolet iS10 FT-IR spectrometer. Samples were prepared for FT-IR measurements by drying suspensions in $\mathrm{KBr}$ salts and pressing them into pellets.

Production of hydrogen was studied using micro- gas chromatography (Varian CP4900). The analysis of $\mathrm{H}_{2}$ evolution was performed using a molecular sieve (5A) equipped with a precolumn and a backflush system to protect the molecular sieve. The amount of $\mathrm{H}_{2}$ produced was determined using a thermal conductivity detector (TCD) with Argon as a reference gas (see supporting information for more details). Formation of ketones was detected using gas chromatography mass spectrometry (GC-MS) and flame ionization detection (GC-FID). Stock solutions containing $1.5 \mu \mathrm{g} / \mathrm{ml}$ of crystalline SiNPs were prepared in various secondary alcohols and 
mixed with water in volume proportions from $1 \%$ to $30 \%$ (description in supporting information). The solutions were mixed in the static headspace (SHS) of the gas chromatograph (GC) where the analysis was performed. A two-way splitter was used to split the signal between the mass spectrometry detector and the flame ionization detector for peak identification, detection, and confirmation of the amounts of ketone produced. A Thermo Scientific glass Ag/AgCl double junction semi-micro tip $\mathrm{pH}$ electrode connected to an Omega microprocessor $\mathrm{pH}$ meter with ATC was used for $\mathrm{pH}$ measurements.

One-dimensional ${ }^{1} \mathrm{H}$ MAS, ${ }^{13} \mathrm{C}$ and ${ }^{29} \mathrm{Si} \mathrm{CP} / \mathrm{MAS}$ solid-state NMR spectra were recorded on Bruker AVANCE III spectrometers operating at $900 \mathrm{MHz}$ resonance frequencies for ${ }^{1} \mathrm{H}$ with a conventional double resonance $3.2 \mathrm{~mm} \mathrm{CP} / \mathrm{MAS}$ probe at a spinning frequency of $20 \mathrm{KHz}$ for ${ }^{1} \mathrm{H}$ and ${ }^{13} \mathrm{C}$ and $10 \mathrm{KHz}$ for ${ }^{29} \mathrm{Si}$. Dry nitrogen gas was utilized for sample spinning to prevent degradation of the samples. NMR chemical shifts are reported with respect to the external references, TMS and adamantine, for ${ }^{1} \mathrm{H}$ and ${ }^{13} \mathrm{C}$. For ${ }^{13} \mathrm{C} \mathrm{CP} / \mathrm{MAS}$ NMR experiments, the following sequence was used: $90^{\circ}$ pulse on the proton (pulse length $2.4 \mathrm{~s}$ ), and then a cross-polarization was achieved using a linear ramp of RF field amplitude on the ${ }^{1} \mathrm{H}$ channel, with a contact time of $2 \mathrm{~ms}$ for $13 \mathrm{C}, 1$ and $10 \mathrm{~ms}$ for ${ }^{29} \mathrm{Si}$. The RF field strength was chosen for optimum transfer efficiency. There was additional acquisition of the NMR signal under SPINAL-64 proton decoupling at a RF field of $100 \mathrm{KHz}$. The delay between the scans was set to $4 \mathrm{~s}$ for ${ }^{13} \mathrm{C}$ and $5 \mathrm{~s}$ for ${ }^{29} \mathrm{Si}$ to allow the complete relaxation of the ${ }^{1} \mathrm{H}$ nuclei and the number of scans was 25,000 for ${ }^{13} \mathrm{C}$, 20,000 for ${ }^{29} \mathrm{Si}$ and 8 for ${ }^{1} \mathrm{H}$. An exponential apodization function corresponding to a line broadening of $40 \mathrm{~Hz}$ for ${ }^{13} \mathrm{C}$ and $100 \mathrm{~Hz}$ for ${ }^{29} \mathrm{Si}$ was applied prior to Fourier transformation.

${ }^{29} \mathrm{Si}$ direct polarization DP/MAS solid-state NMR spectra were recorded on Bruker AVANCE III spectrometers operating at $900 \mathrm{MHz}$ resonance frequencies for ${ }^{1} \mathrm{H}$ with a conven- 
tional double resonance $3.2 \mathrm{~mm}$ probe at a spinning frequency of $10 \mathrm{KH}$ with an excitation pulse of $30^{\circ}$ and a recovery time of $120 \mathrm{~s}$ and the number of scans was 10,000 .

${ }^{1} \mathrm{H}-{ }^{1} \mathrm{H}$ multiple-Quantum Spectroscopy: Two-dimensional double-quantum (DQ) and triple-quantum (TQ) experiments were recorded a Bruker AVANCE III spectrometer operating at $900 \mathrm{MHz}$ with a conventional double resonance $3.2 \mathrm{~mm}$ CPMAS probe, according to the following general scheme: excitation of DQ coherences, $t_{1}$ evolution, Z-filter, and detection. The spectra were recorded in a rotor synchronized fashion in $t_{1}$; that is, the $t_{1}$ increment was set equal to one rotor period $(4.545 \mu \mathrm{s})$. One cycle of the standard back-to-back (BABA) recoupling sequence was used for the excitation and reconversion period. Quadrature detection in $w_{1}$ was achieved using the States-TPPI method. A spinning frequency of $22 \mathrm{KHz}$ was used. The $90^{\circ}$ proton pulse length was $2.5 \mu \mathrm{s}$, while a recycle delay of $5 \mathrm{~s}$ was used. A total $32 t_{1}$ increments with 32 scans each were recorded. Double (DQ)- and Triple (TQ)-quantum proton spectroscopies under fast MAS have recently been shown to be powerful techniques to probe the structural information and dynamics inherent proton-proton dipolar couplings. The DQ frequency in the $w_{1}$ dimension corresponds to the sum of two single quantum (SQ) frequencies of the two coupled protons and correlates in the $w_{2}$ dimension with the two corresponding proton resonances. The TQ frequency in the $w_{1}$ dimension corresponds to the sum of the three SQ frequencies of the three coupled protons and correlates in the $w_{2}$ dimension with the three individual proton resonances. Conversely, groups of less than three equivalent spins will not give rise to diagonal signals in the spectrum. Two-dimensional DQ and TQ correlations experiments can thus be applied to determine in a reliable way the number of attached equivalent protons.

\section{RESULTS AND DISCUSSION}


In a typical experiment, $1.5 \mu \mathrm{g}$ of SiNPs that are $2.5 \mathrm{~nm}$ in diameter are mixed with a water solution of isopropanol (33 mmoles). Hydrogen is evolved ${ }^{29}$ (Figure 2 and see Figure S6 in SI) and detected by micro-GC (micro- gas chromatography), acetone is formed and is detected by GC-MS (Figure 3 and see supporting information) in equimolecular amounts.

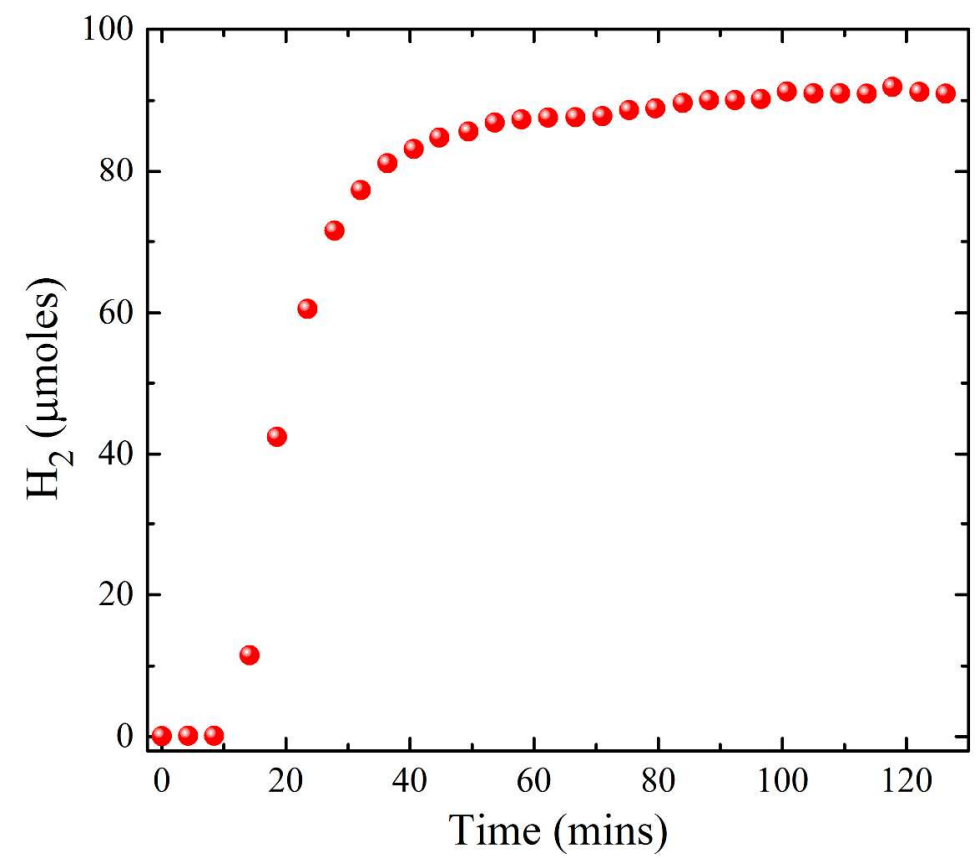

Figure 2. The amount of hydrogen produced during the reaction of $30 \%$ SiNPs suspended in isopropanol mixed with $\mathrm{H}_{2} \mathrm{O}$ as a function of time. Water and IPA are mixed in the 7:3 proportions. The amount of $\mathrm{Si}$ in this experiment is $4.5 \times 10^{-6} \mathrm{~g}$.

Figure 2 shows hydrogen evolution during the catalytic reaction where Isopropanol containing Si-NPs is mixed with water. The molar amount of hydrogen produced at any given time is equal to the molar amount of acetone produced at the same time. Using a high resolution GC-MS we measured the amount of Acetone produced right after the nanoparticles are mixed with the water and alcohol solution. The amount produced as a function of SiNPs present in solution is plotted in figure 3. (The details of the detection is given in the supporting information.) 


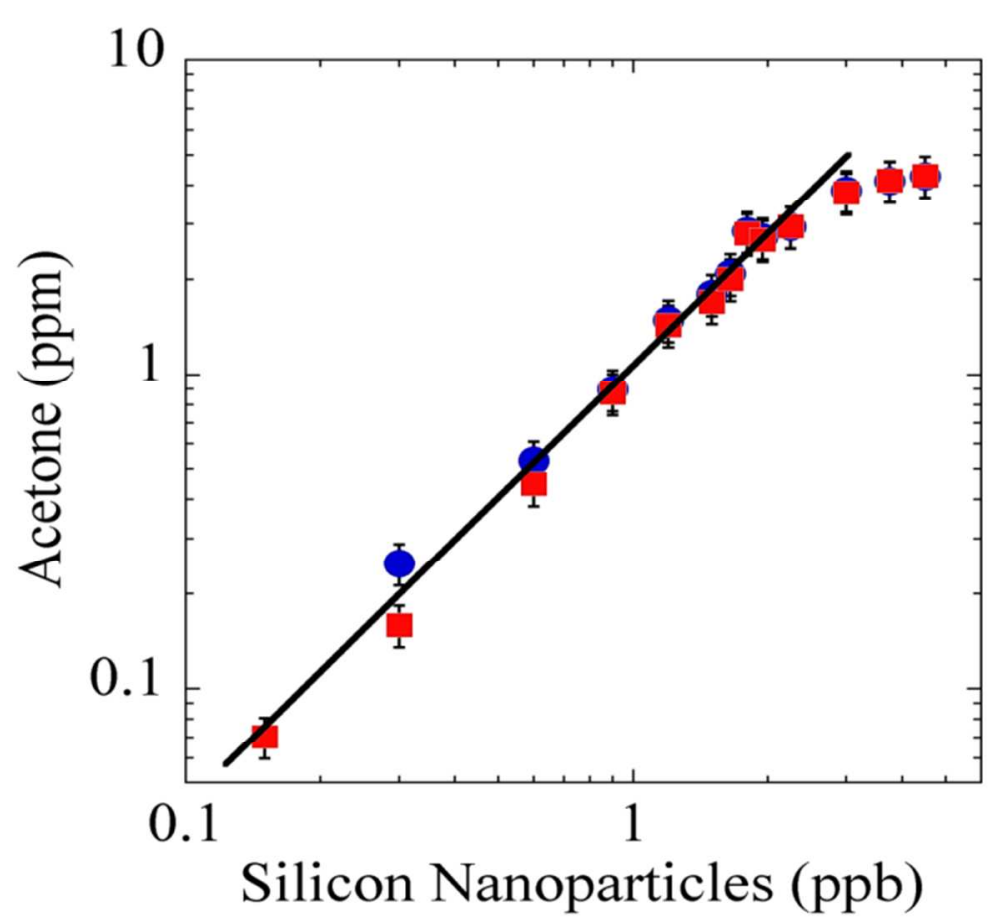

Figure 3. Amount of acetone in ppm produced during the catalytic reaction as a function of the concentration of SiNPs, in ppb by weight, contained in the IPA solution. Blue circles correspond to GC-FID results and the red squares correspond to GC-MS results. The line is a fit to a power law: [Acetone] $\sim[\mathrm{Si}]^{3 / 2}$. There is a ratio of 1000 to 1 between the numbers of acetone molecules and silicon NPs. These data were retrieved from kinetics experiments (Figure S7 in SI).

The fit to the data shown in Figure 3 is captured by the following power law, which shows that only surface atoms interacted with the solvent atoms: $[$ Acetone $] \sim[\mathrm{Si}]^{3 / 2}$, where $[$ Acetone] is the concentration of acetone in $\mathrm{mg} / \mathrm{ml}$ and [ $\mathrm{Si}$ ] is the concentration of silicon nanoparticles in $\mu \mathrm{g} / \mathrm{l}$. A heuristic model of a surface reaction within a shell around the particles explains this reaction. Let $\rho_{S i}$ be the density of silicon atoms that participate in the reaction. Since these atoms are fixed on the surface, they are related to the surface of the particles by the surface density given by $\rho_{S i} \sim \mathrm{M} / l^{2}$, where $l^{2}$ is the surface of the nanoparticle. On the other hand, the density of acetone is given by $\rho_{\text {Acetone }} \sim \mathrm{M} / \mathrm{L}^{3}$, where $\mathrm{L}^{3}$ is the volume at which the acetone is produced. If 
these length scales are equal $(l=\mathrm{L})$, meaning that the acetone exists in the same volume around the particles, then the densities are related by $\rho_{\text {Acetone }} \sim \rho_{S i}{ }^{3 / 2}$ which is the correct fit of the data represented by the line. This simple argument enforces the idea that only surface silicon atoms contribute to the reaction and that only chemisorbed alcohols contribute to this process as demonstrated below using NMR.

To demonstrated the recyclability of the SiNPs we measured the rate of the reaction and found that, after the plateau value (Figure S7) we could start a new reaction by adding more water and we notice that more acetone is produced: The particles are recycled. We chose one ratio of water concentration to IPA containing the nanoparticles and performed GC-FID. Figure 4 shows the renewed activity when more water is added and when the kinetics reach a plateau (kinetic figures are depicted in Figure S7 in SI). This proves that the nanoparticles are not consumed during the reaction.

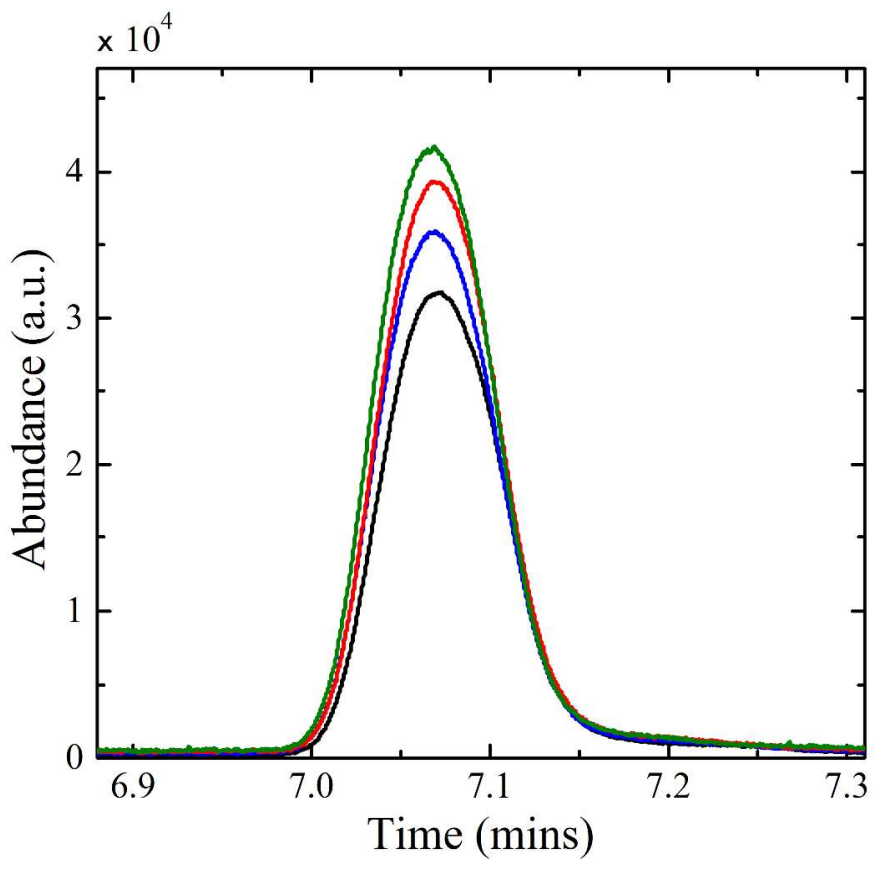

Figure 4. GC-FID chromatogram of $1.5 \mathrm{ml}$ of SiNPs-containing IPA in $3 \mathrm{ml}$ of water (black), the concentration of $\mathrm{Si}$ in this experiment is $1.5 \mu \mathrm{g} / \mathrm{ml}$ of IPA. The peak response is directly propor- 
tional to the amount of acetone produced. Notice the increase in the peak response when $1.5 \mathrm{ml}$ of water is added, successively (blue, red and green spectra), to the original suspension (black spectrum). Water is added when the kinetics curve flattens out and no more acetone is produced (Figure S7)

When increasing the amount of SiNPs, the pH drops exponentially with the amount of SiNPs added (Figure 5 shows the amount of protons produced when assuming that the mixture behave like a weak acid.). Notice that IPA mixed with water gives away more protons than any other solvent tested. Furthermore, the photoluminescence of these SiNPs are only slightly affected by this catalytic phenomenon (no variation of the structure as described in Figure S4 in supporting information). We are obviously dealing with a catalytic phenomenon, for which we tried to investigate the mechanism ${ }^{1} \mathrm{H},{ }^{13} \mathrm{C}$ and ${ }^{29} \mathrm{Si}-\mathrm{NMR}$

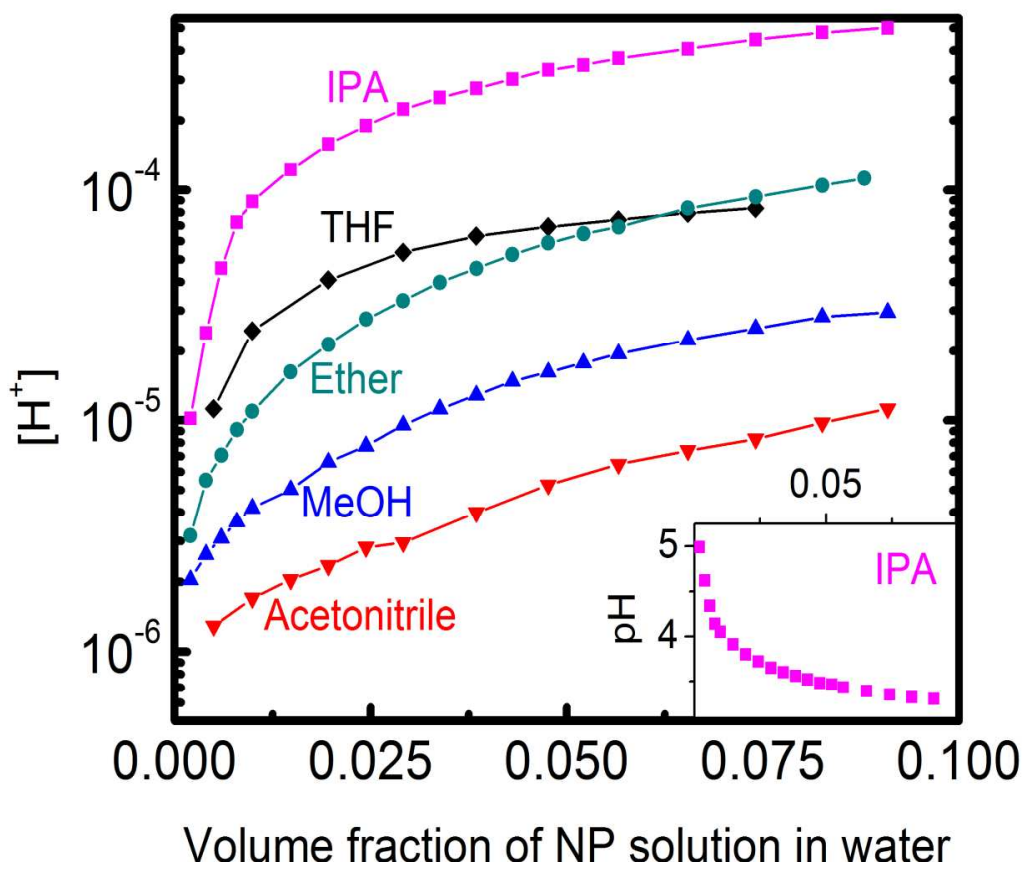

Figure 5. $\mathrm{H}^{+}$ions (protons) produced as a function of the addition of silicon nanoparticles (SiNPs) suspended in solvents and mixed with water at different volume fractions. The volume fraction of water to IPA varies from $100 \%$ to $90 \%$. The initial concentration of silicon nanoparti- 
cles is $1.5 \mu \mathrm{g} / \mathrm{ml}$. The inset shows the dramatic decrease in the $\mathrm{pH}$ after adding SiNPs contained in IPA.

To determine and confirm that the surface silicon atoms react with IPA, we conducted extensive solid-state NMR experiments in which we observed the disappearance of the $\mathrm{OH}$ peaks of isopropanol and the appearance of a new resonances corresponding to protons on the surface of the particles. The ${ }^{1} \mathrm{H}$ magic-angle spinning (MAS) solid-state NMR spectrum of SiNPs suspended in IPA exhibits three signals at 1.5, 4.3 and 5.6 ppm (Figures 6A and Figure S14 in supporting information). The signal at $1.5 \mathrm{ppm}$ in Figure $6 \mathrm{~B}$ auto-correlates in the double-quantum (DQ) NMR experiment under $22 \mathrm{KHz} \mathrm{MAS},{ }^{30,31}$ which can be assigned to $\mathrm{CH}_{\mathbf{3}}$ of isopropanol. The peak at $4.3 \mathrm{ppm}$ exhibits no autocorrelation in the DQ experiment and is assigned to the proton $\mathrm{CH}$ of isopropanol. Figure S14 shows that the solution ${ }^{1} \mathrm{H}$ NMR spectrum of isopropanol has the same chemical shifts. Furthermore, a correlation in the DQ/single-quantum (SQ) NMR spectrum between $\mathbf{C H}$ and $\mathrm{CH}_{3}$ confirms the assignment of these two kinds of protons to IPA (Figure 7B). The ${ }^{13} \mathrm{C} \mathrm{CP/MAS} \mathrm{NMR} \mathrm{spectrum} \mathrm{shows} \mathrm{two} \mathrm{peaks} \mathrm{at} 63$ and $25 \mathrm{ppm}$ corresponding to $\mathrm{CH}$ and $\mathrm{CH}_{3}$ of isopropanol, respectively (Figure S15 in supporting information). In Figure 7A, we observe that the peak at $2.1 \mathrm{ppm}$, characteristic of $\mathrm{OH}$ (Figure $\mathrm{S} 16$ in supporting information), is absent in the $1 \mathrm{D}{ }^{1} \mathrm{H}$ MAS spectrum, suggesting that a bond-forming reaction taking place between isopropanol and the SiNP surface. The new peak at $5.6 \mathrm{ppm}$ exhibits no autocorrelation in the DQ spectrum that can be assigned to an isolated proton on the surface of the SiNPs. 


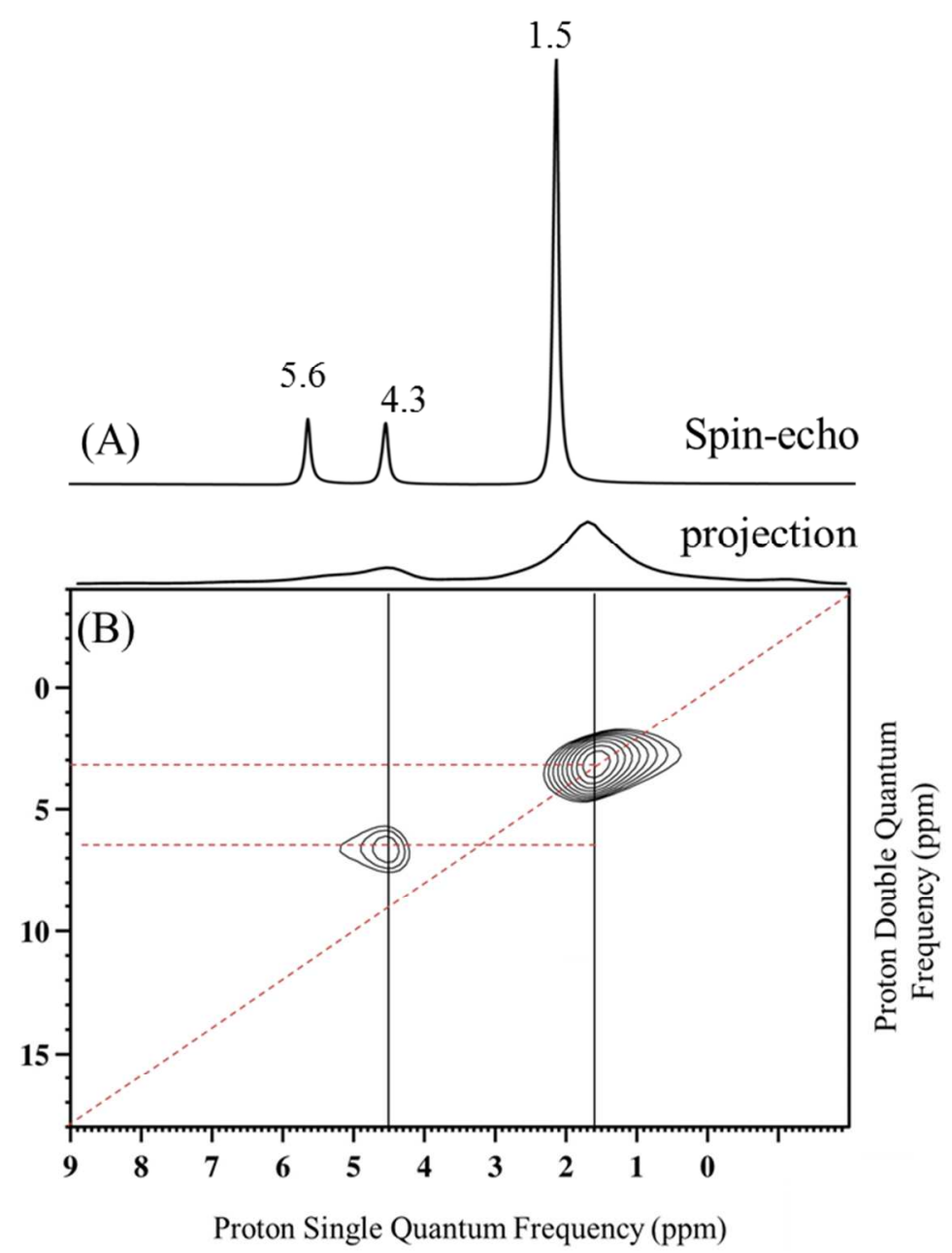

Figure 6. (A) One-dimensional (1D) ${ }^{1} \mathrm{H}$ spin-echo MAS solid-state NMR spectrum of SiNPs suspended in isopropanol acquired at $900 \mathrm{MHz}$ with a $22 \mathrm{KHz}$ MAS frequency, a repetition delay of $5 \mathrm{~s}$, and 8 scans. (B) Two-dimensional (2D) ${ }^{1} \mathrm{H}^{-1} \mathrm{H}$ double-quantum (DQ)/Single-Quantum (SQ) NMR spectra of SiNPs suspended in isopropanol acquired with 32 scans per $t_{1}$ increment, 5 $\mathrm{s}$ repetition delay, 32 individual $t_{1}$ increments.

To understand this proton coordination, we prepared two concentrations (30 and 15\%) of SiNPs with IPA in $\mathrm{H}_{2} \mathrm{O}$ and evaporated them at 50 mbar and room temperature for 85 minutes using a Vacuum RapidVap (Labconco, Inc.). The ${ }^{1} \mathrm{H}$ NMR spectra in Figure 7A and 7B show a clear increase in intensity and a small shift in the peak at $5.3 \mathrm{ppm}$ in both concentrations. The ${ }^{1} \mathrm{H}$ NMR spectra of water shows a sharp peak at $4.2 \mathrm{ppm}$ (Figure S17 in supporting information) and 
the line fittings of the ${ }^{1} \mathrm{H}$ MAS NMR spectra of the $30 \%$ concentration (Figure S18 in supporting information) and the $15 \%$ concentration (Figure S19 in supporting information) ruled out the possibility of the presence of water. The autocorrelation in the DQ and Triple-Quantum (TQ) spectra for the peak at $5.3 \mathrm{ppm}$ (Figure 7), however, in the $15 \%$ concentration of IPA containing SiNPs in water, suggests that the density of protons at the surface of the NPs is higher than when no water is added (Figure 6). This suggests an increase in the population of Si-H on the surface. 


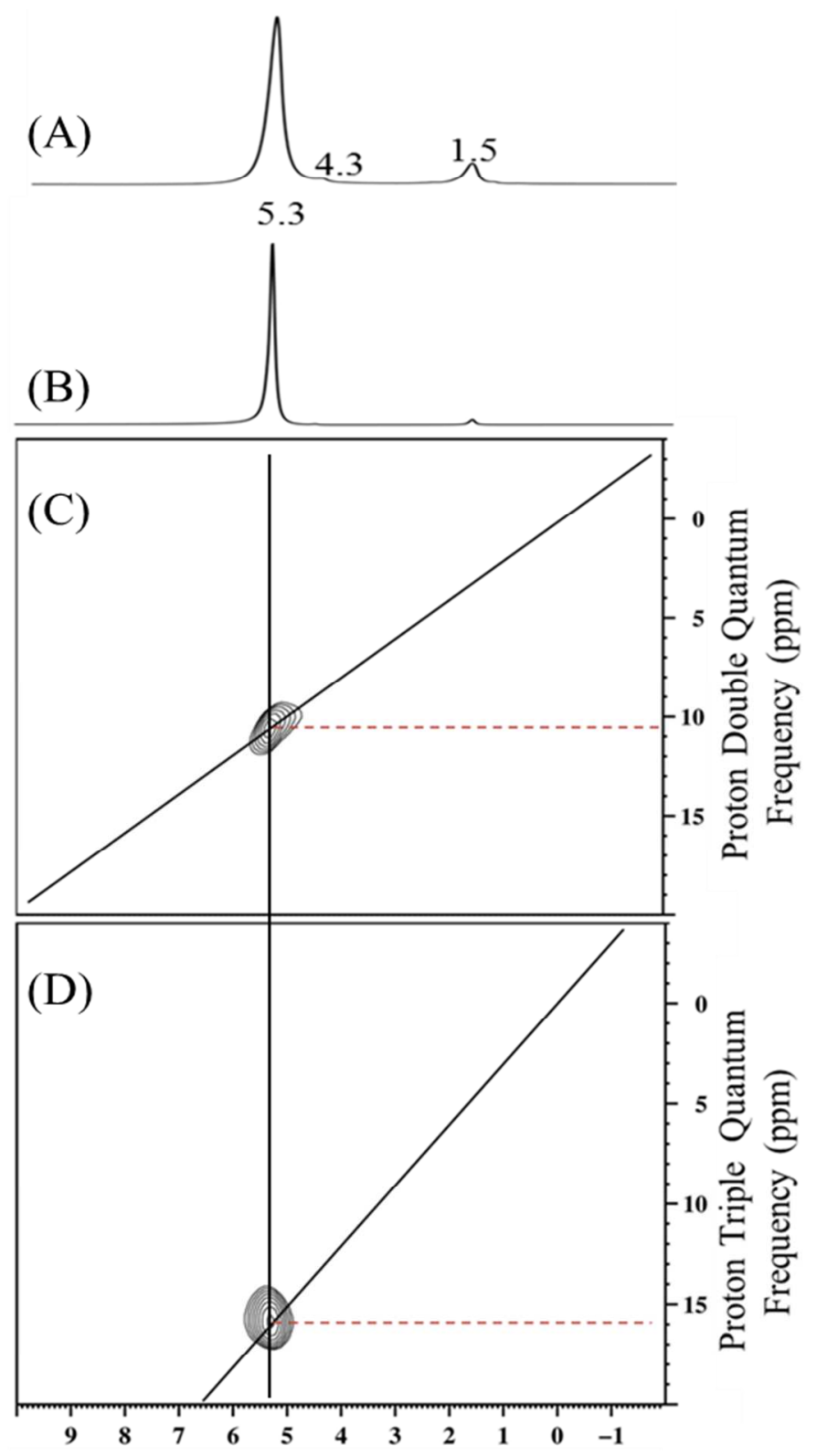

Proton Single Quantum Frequency (ppm)

Figure 7. $1 \mathrm{D}{ }^{1} \mathrm{H}$ spin-echo MAS solid-state NMR spectrum of (A) $30 \%$ (B) $15 \%$ SiNPs suspended in isopropanol in $\mathrm{H}_{2} \mathrm{O}$ acquired at $900 \mathrm{MHz}$ with a $22 \mathrm{KHz}$ MAS frequency, a repetition delay of $5 \mathrm{~s}$, and 8 scans. (C) $2 \mathrm{D}^{1} \mathrm{H}-{ }^{1} \mathrm{H}$ double-quantum (DQ)/Single-Quantum (SQ) (D) $2 \mathrm{D}{ }^{1} \mathrm{H}-$ ${ }^{1} \mathrm{H}$ Triple-quantum (TQ)/Single-Quantum (SQ) NMR spectra of $15 \%$ SiNPs suspended in isopropanol in $\mathrm{H}_{2} \mathrm{O}$ acquired on $900 \mathrm{MHz}$ NMR spectrometer under $22 \mathrm{KHz}$ MAS frequency with 
32 scans per $t_{1}$ increment, $5 \mathrm{~s}$ repetition delay, 32 individual $t_{1}$ increments. The mass of SiNPs is the same as above.

To confirm the existence of protons at the surface of the NPs and the existence of the Si$\mathrm{H}$ species, we used direct-polarization (DP) and cross-polarization (CP) ${ }^{29} \mathrm{Si}$ NMR on SiNPs suspended in isopropanol (Figure 8) and 30\% of SiNPs suspended in isopropanol in $\mathrm{H}_{2} \mathrm{O}$ after evaporation (Figure 9). The ${ }^{29} \mathrm{Si} \mathrm{T}_{1}$ was reported to be $12,000 \mathrm{~s}$ for crystalline silicon nanoparticles. ${ }^{32}$ Therefore, in the DP experiment, an excitation pulse of $30^{\circ}$ and a recovery time of $120 \mathrm{~s}$ were used to give us a qualitative but not quantitative signal, especially between the bulk and the surface silicon atoms. The DP MAS spectrum of SiNPs suspended in isopropanol (Figure 8) reveals a distribution of peaks between -30 and -70 ppm and centered around -50 ppm and largely unaffected by the removal of ${ }^{1} \mathrm{H}$ decoupling. These peaks are therefore due to silicon atoms that are not directly bonded to hydrogen atoms and can be assigned to crystalline silicon nanoparticles.

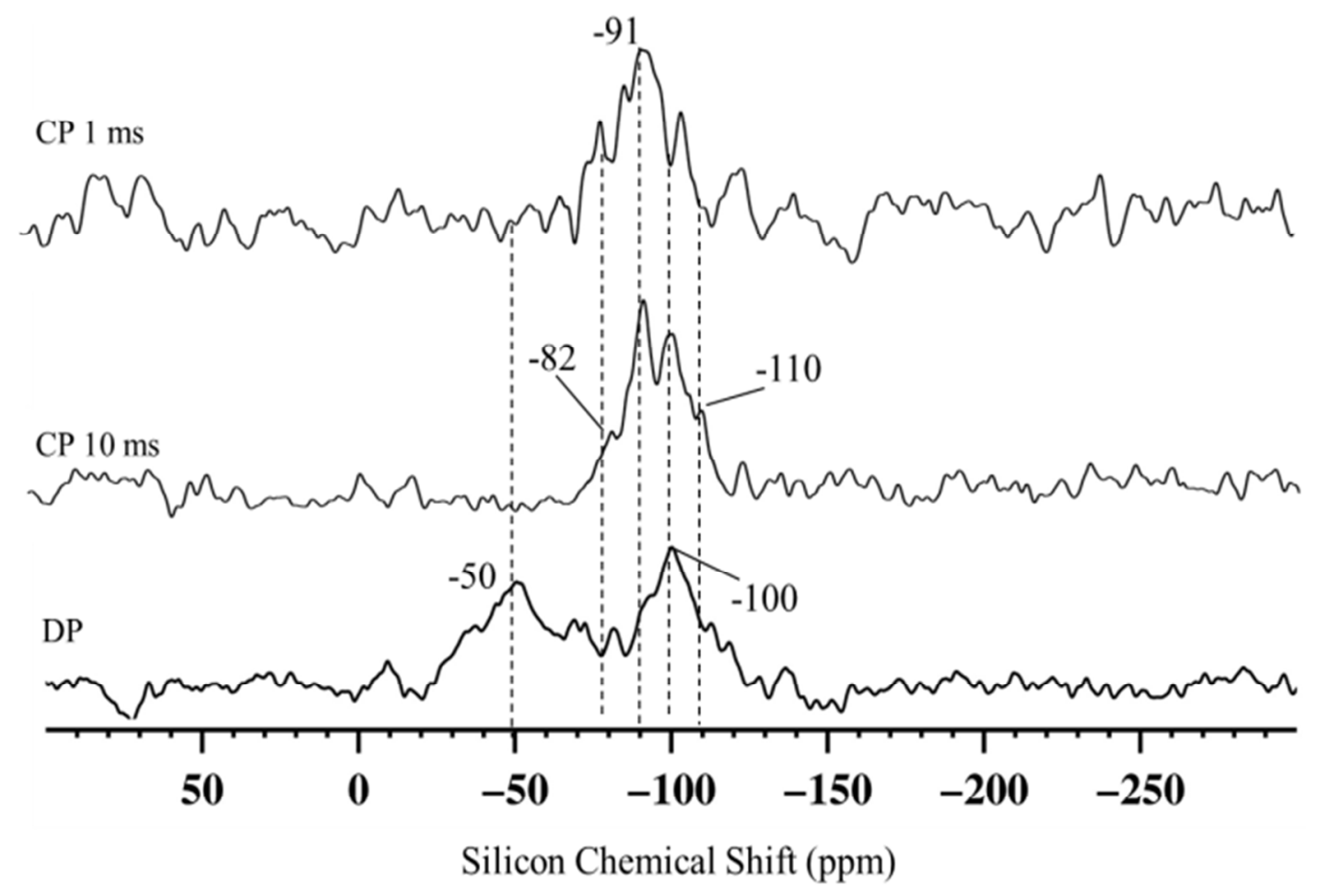


Figure 8. ${ }^{29} \mathrm{Si}$ NMR spectrum of SiNPs suspended in isopropanol using the direct-polarization (DP/MAS) acquired on a $900 \mathrm{MHz}$ NMR spectrometer at $10 \mathrm{KHz}$ MAS frequency with an excitation pulse of 300 and a recovery time of $120 \mathrm{~s}$ and 10,000 scans. The cross-polarization (CP/MAS) NMR spectrum of the same sample with two different contact times (10 and $1 \mathrm{~ms})$ acquired at $900 \mathrm{MHz}$ with a $10 \mathrm{kHz}$ MAS frequency. The number of scans was 20,000, and the recycle delay was set to $5 \mathrm{~s}$. An exponential line broadening of $100 \mathrm{~Hz}$ was applied prior to the Fourier transform.

Another peak distribution between -90 and $-120 \mathrm{ppm}$ and centered around $-100 \mathrm{ppm}$ was detected. It was affected by ${ }^{1} \mathrm{H}^{29}{ }^{29} \mathrm{Si} \mathrm{CP} / \mathrm{MAS}$ decoupling with different contact times, suggesting that this peak was due to the silicon atoms on the surface. ${ }^{33}$ The CP technique is based directly upon dipole-dipole ${ }^{1} \mathrm{H}^{29}{ }^{29} \mathrm{Si}$ interactions and favors ${ }^{29} \mathrm{Si}$ signals of silicon atoms that are directly bonded to hydrogen atoms or close to each other because of the short contact time. We used a long contact time to probe if the $\mathrm{Si}$ atoms were attached to other $\mathrm{Si}$ atoms by $\mathrm{Si}-\mathrm{Si}$ bonds or by Si-O-Si bonds. The difference between DP and CP can be understood on the basis that only DP can probe if the surface Si atoms are bonded to hydrogen. The CP/MAS spectra of SiNPs suspended in isopropanol using a long contact time $(10 \mathrm{~ms})$ shows the disappearance of the peaks around $-50 \mathrm{ppm}$ and a clear distribution at $-82,-91,-100$ and $-110 \mathrm{ppm}$, indicating that the surface atoms are bonded exclusively to hydrogen atoms. However, the CP/MAS with a short contact time $(1 \mathrm{~ms})$ showed a few distributions with a higher intensity at -91 ppm that can be attributed to silicon atoms directly bonded to hydrogen. The DP for the $30 \%$ concentration of SiNPs suspended in IPA and mixed with $\mathrm{H}_{2} \mathrm{O}$ shows higher intensities for the peak distributions around -100 ppm, suggesting an increased population of protons on the surface (Figure 9). 


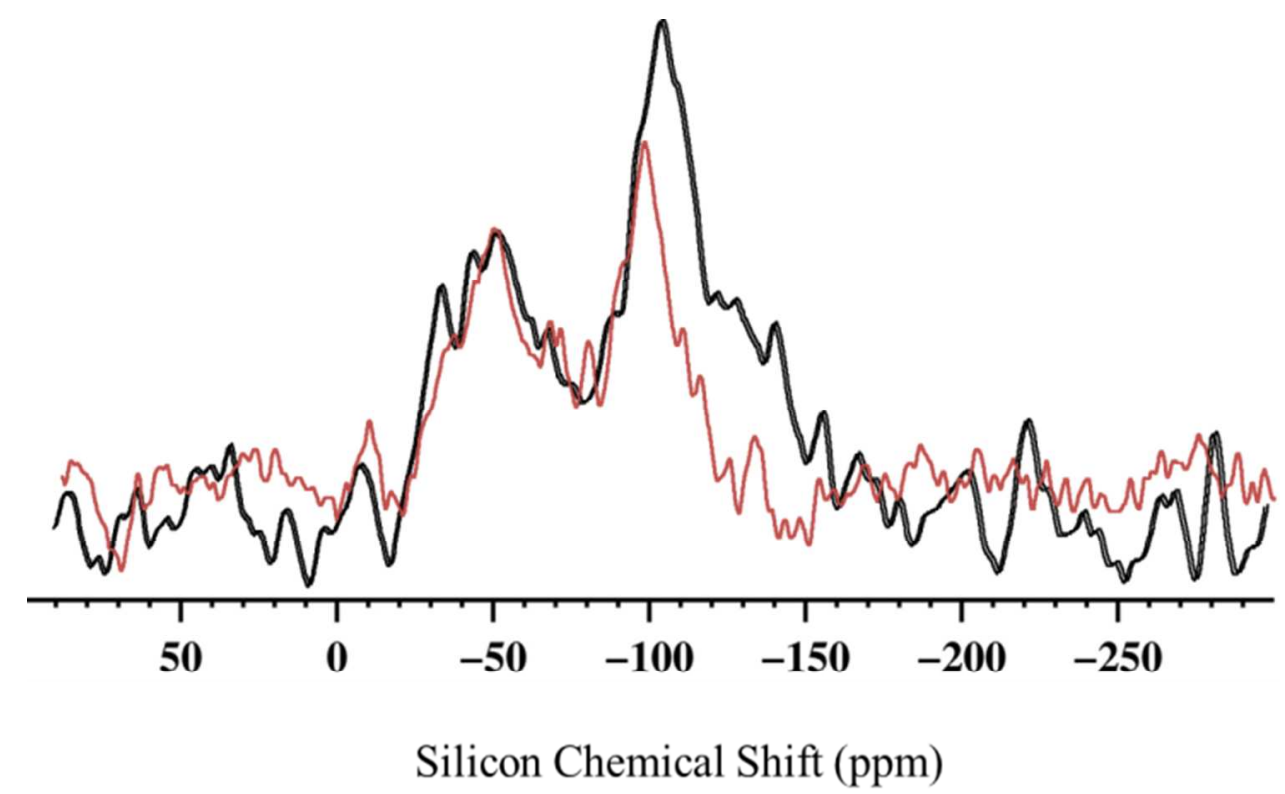

Figure 9. ${ }^{29} \mathrm{Si}$ NMR spectra of the $30 \%$ concentration of SiNPs suspended in isopropanol mixed with $\mathrm{H}_{2} \mathrm{O}$ (black) and SiNPs suspended in isopropanol (red) using direct-polarization (DP/MAS) acquired on a $900 \mathrm{MHz}$ NMR spectrometer using $10 \mathrm{KHz}$ MAS frequency with an excitation pulse of $30^{\circ}$ and a recovery time of $120 \mathrm{~s}$, and 10,000 scans.

The "dissociative chemisorption" of isopropanol occurs on the SiNPs to produce an Si-H and an Si-isopropoxy radical. There are two possible mechanisms (Figure 10) for isopropanol chemisorption depending on the nature of the surface chemistry: if the SiNPs is covered by oxygen (e.g. bridging oxygen probably from water) dissociative chemisorption of isopropanol occurs as in mechanism $\mathrm{A}$ in Figure 10. However this does not explain the formation of protons (decrease of $\mathrm{pH}$ ) and the formation of $\mathrm{Si}-\mathrm{H}$ demonstrated by NMR.

In contrast and given the NMR results as well as the FTIR spectra (Figure S1) we can safely assume that the SiNPs are not fully covered by oxygen, and one can tentatively propose mechanism B where the surface of the SiNPs contains disilene and monohydride ( $\mathrm{Si}-\mathrm{H})$ species as in Figure 10-mechanism B. (Si-H being electron-deficient could serve as electron sinks) First isopropanol dissociated on a highly electron deficient " $\mathrm{Si}=\mathrm{Si}$ " with formation of isopropoxy sili- 
con detected by NMR and a proton detected by $\mathrm{pH}$ measurements. Once the isopropoxy is chemisorbed, the next step of the mechanism is the beta-H elimination with formation of acetone and silicon hydride that was detected by NMR. This silicon hydride can react with protons to give hydrogen. There would be two competitive reactions with the silicon hydride: A reaction with protons to give hydrogen or simple adsorption. 


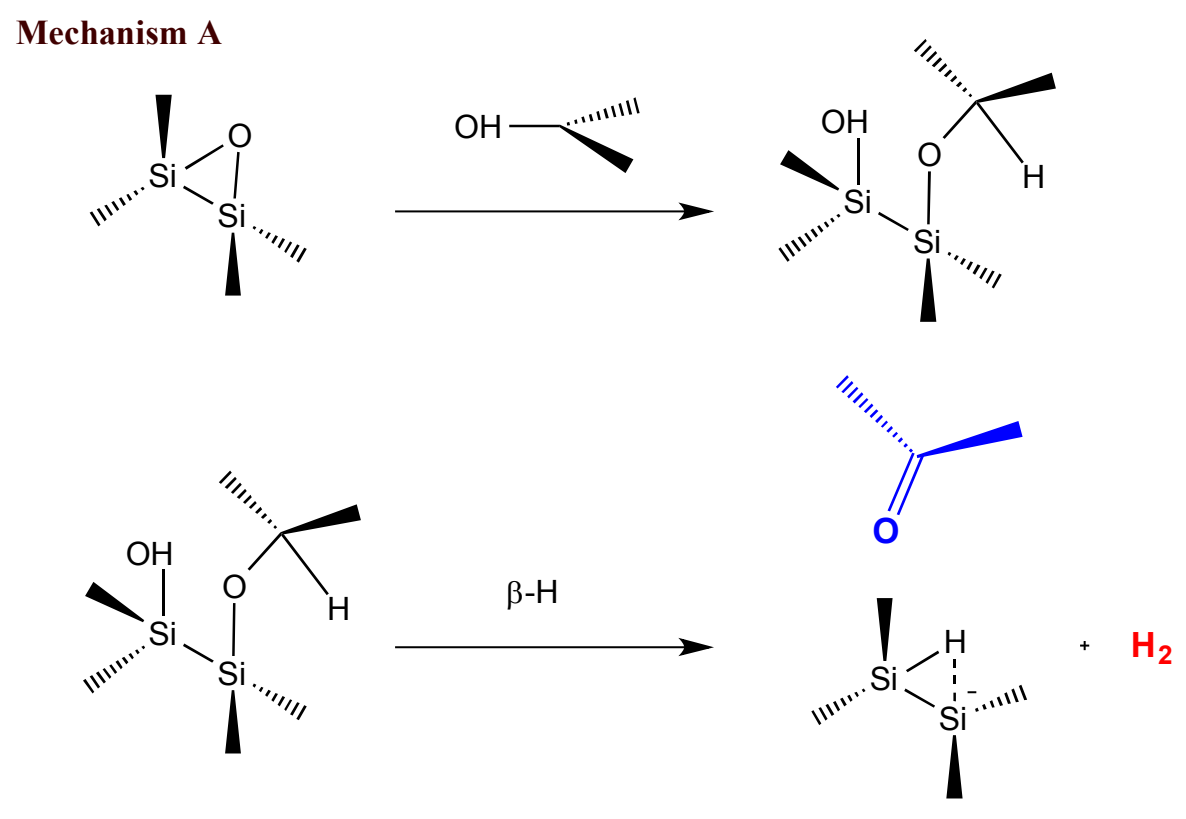

Mechanism B
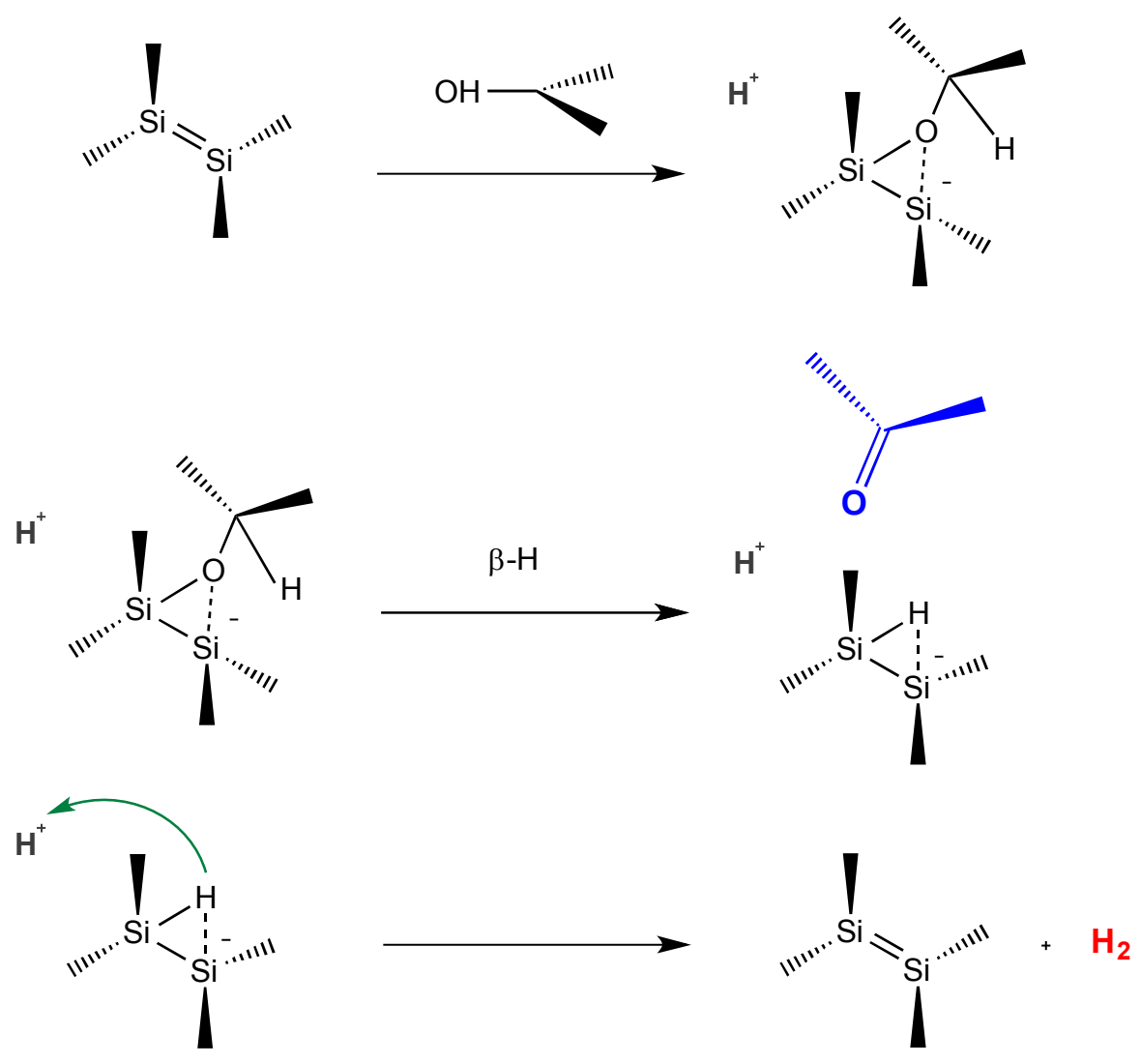

52

53

54

55

56

57

58

59

60 
Figure 10. The two possible mechanisms for Acetone production, but only the mechanism B reproduce our results that were probed by NMR and $\mathrm{pH}$ measurements where the surface the nanoparticles is made of disilene bonds. The oxygen from Isopropoxy radical is a Hapto-2 Oxygen.

\section{CONCLUSION}

We have demonstrated the ability of silicon nanoparticles to be an efficient and recyclable catalyst for the dehydrogenation of a series of secondary alcohols. Ketones are produced (acetone in the case of Isopropyl alcohol) and hydrogen is evolved. The catalytic activity and performance is related solely to the surface composition. The presence of the $\mathrm{Si}-\mathrm{H}$ bonds on the surface that are electron sinks may be necessary for the ketone production but our preliminary results show that the presence of disilene or $\mathrm{Si}=\mathrm{Si}$ is necessary for the hydrogen evolution.

\section{ASSOCIATED CONTENT}

\section{Supporting Information Available}

Fourier Transform Infrared Spectroscopy (FTIR). Study of the effect of water on luminescence of silicon nanoparticles; along with the corresponding photoluminescence emission spectra. Discussion about the evidence of charge transfer; supported by $\mathrm{pH}$ measurements of silicon nanoparticles colloidal/water solutions. Gas chromatography for ketone production (GC-MS and GCFID) from various secondary alcohols. ${ }^{1} \mathrm{H}$ liquid-state and solid-state magnetic resonance (NMR) spectroscopy as well as ${ }^{13} \mathrm{C}$ and ${ }^{29} \mathrm{Si}$ solid-state NMR. This material is available free of charge via the Internet at http://pubs.acs.org.

\section{AUTHOR INFORMATION}

\section{Corresponding Author}

* sahraoui.chaieb@kaust.edu.sa 


\section{Author Contributions}

J.E. prepared all samples, did the GC-MS and micro-GC experiments as well as FT-IR, assisted with the photoluminescence, UV-Vis absorption measurements and the NMR experiments, and formatted the paper. C.H. prepared samples and did the $\mathrm{pH}$ as well as the UV-Vis absorption measurements. E.A. performed solid-state NMR experiments and analysis. Y.S. assisted with the micro-GC-TCD for the hydrogen detection. Z.E. assisted with GC-MS for the ketones detection. S.C. designed the experiments, wrote the paper and analyzed the data. All authors have given approval to the final version of the manuscript.

\section{ACKNOWLEDGMENT}

S.C. thanks J.-M. Basset for fruitful discussions and critical reading of the manuscript. We thank N. Kharbatia for his assistance with the GC-MS, and A. Emwas for his work on liquid NMR but not discussed in this paper. S.C. thanks Kun Li for assisting in acquiring the HRTEM image. We also thank King Abdullah University of Science and Technology (KAUST) for financial support.

\section{REFERENCES}

1. Alivisatos, A. P. Semiconductor Clusters, Nanocrystals and Quantum Dots. Science 1996, 271, 933-937.

2. Roduner, E. Size Matters: Why Nanomaterials are Different. Chemical Society Reviews 2006, 35, 583-592.

3. Elghanian, R.; Storhoff, J. J.; Mucic, R. C.; Letsinger, R. L.; Mirkin, C. A. Selective Colorometric Detection of Polynucleotides Based on the Distance-Dependent Optical Properties of Gold Nanoparticles. Science 1997, 277, 1078-1081.

4. Colvin, V. L.; Schlamp, M. C.; Alivisatos, A. P. Light-Emitting Diodes made from Cadmium Selenide Nanocrystals and a Semiconducting Polymer. Nature 1994, 370, 354-357. 
5. Belomoin, G.; Therrien, J.; Smith, A.; Rao, S.; Twesten, R.; Chaieb, S.; Nayfeh, M. H.; Wagner, L.; Mitas, L. Observation of a Magic Discrete Family of Ultrabright Si Nanoparticles. Appl. Phys. Lett. 2002, 80, 841-843.

6. Weigele, P.; Noren, C. J. Photocatalysts: Splitting Water with Viruses. Nature Nanotechnology 2010, 5, 313-314.

7. Segev-Bar; M., Haick, H. Flexible Sensors Based on Nanoparticles. ACS Nano 2013, 7, 8366-8378.

8. Valden, M.; Lai, X.; Goodman, D. W. Onset of Catalytic Activity of Gold Clusters on Titania with the Appearance of Nonmetallic Properties. Science 1998, 281, 1647-1650.

9. Narayanan, R.; El-Sayed, M. A. Catalysis with Transition Metal Nanoparticles in Colloidal Solution: Nanoparticle Shape Dependence and Stability. J. Phys. Chem. B 2005, 109, $12663-12676$.

10. Burda, C; Chen, X; Narayanan, R; El-Sayed, M. A. Chemistry and Properties of Nanocrystals of Different Shapes. Chem. Rev. 2005, 105, 1025-1102.

11. Xia, Y.; Xiong, Y.; Lim, B.; Skrabalak, S. E. Shape-Controlled Synthesis of Metal Nanocrystals: Simple Chemistry Meets Complex Physics. Angew. Chem., Int. Ed. 2009, 48, 60-103.

12. Corma, A. State of the Art and Future Challenges of Zeolites as Catalysts. J. Catal. 2003, $216,298-312$.

13. Zhou, K.; Li, Y. Catalysis Based on Nanocrystals with Well-Defined Shapes. Angew. Chem., Int. Ed. 2012, 51, 602-613.

14. Aiken III, J. D.; Finke, R. G. A Review of Modern Transition-Metal Nanoclusters: their Synthesis, Characterization, and Applications in Catalysis. J. Mol. Catal. A: Chem. 1999, 145, $1-44$. 
15. Hughes, M. D.; Xu, Y.; Jenkins, P.; McMorn, P.; Landon, P.; Enache, D. I.; Carley, A. F.; Attard, G. A.; Hutchings, G. J.; King, F.; Stitt, E. H.; Johnston, P.; Griffin, K.; Kiely, C. J. Tunable Gold Catalysts for Selective Hydrocarbon Oxidation under Mild Conditions. Nature 2005, 437, 1132-1135.

16. Lin, Y.; Finke, R. G. Novel Polyoxoanion- and Bu4N+-Stabilized, Isolable, and Redissolvable, 20-30-.ANG. Ir300-900 Nanoclusters: The Kinetically Controlled Synthesis, Characterization, and Mechanism of Formation of Organic Solvent-Soluble, Reproducible Size, and Reproducible Catalytic Activity Metal Nanoclusters. J. Am. Chem. Soc. 1994, 116, 83358353.

17. Burch, R. Gold Catalysts for Pure Hydrogen Production in the Water-gas Shift Reaction: Activity, Structure and Mechanism. Phys. Chem. Chem. Phys. 2006, 8, 5483-5500

18. Reetz, M. T.; Breinbauer, R.; Wanninger, K. Suzuki and Heck Reactions Catalyzed by Performed Palladium Clusters and PalladiumNickel Bimetallic Clusters. Tetrahedron Lett. 1996, 37, 4499-4502.

19. Lewis, L. N.; Lewis, N. Platinum-Catalyzed Hydrosilation-Colloid Formation as the Essential Step. J. Am. Chem. Soc. 1986, 108, 7228-7231.

20. Shao, M.; Cheng, L.; Zhang, X.; Duo Ma, D. D.; Lee, S. Excellent Photocatalysis of HFtreated Silicon Nanowires. J. Am. Chem. Soc. 2009, 131, 17738-17739.

21. Xu, Y.; Wang, L.; Jiang, W.; Wang, H.; Yao, J.; Guo, Q.; Yuan, L.; Chen, H. Silicon Nanowire Arrays - A New Catalyst for the Reduction of Nitrobenzene Derivatives. ChemCatChem 2013, 5, 3788-3793.

22. Wang, H.; Jiang, W.; Yuan, L.; Wang, L.; Chen, H. Reductase-like Activity of Silicon Nanowire Arrays. ACS Appl. Mater. Interfaces 2013, 5, 1800-1805. 
23. Hwang, Y. J.; Boukai, A.; Yang, P. High Density n-Si/n-TiO 2 Core/Shell Nanowire Arrays with Enhanced Photoactivity. Nano Lett. 2009, 9, 410-415.

24. Raabe G.; Michl J. Multiple Bonding to Silicon. Chem. Rev. 1985, 85, 419-509.

25. Haruta, M. Size- and Support Dependency in the Catalysis of Gold. Catal. Today 1997, 36, $153-166$.

26. Nondek, L.; Seldlacek J. Mechanism of Dehydrogenation of Secondary Alcohols on Chromia. J. Catal. 1975, 40, 34-39.

27. Rioux, R.; Vannice, M. Hydrogenation/Dehydrogenation Reactions: Isopropanol Dehydrogenation over Copper Catalysts. J. Catal. 2003, 216, 362-376.

28. Cunningham, J.; Al-Sayyed, G. H.; Cronin, J. A.; Healy, C.; Hirschwald, W. Surface Synergisms between Copper and its Oxides in Catalytic Isopropanol/Acetone Interconversions at 430-523 K. Appl. Catal. 1986, 25, 129-138.

29. Chaieb, S.; Holt, C. Silicon Hydride Nanocrystals as Catalysts for Proton Production in Water-organic Liquid Mixtures. U.S. Patent 8,795,906 B2 (5 August 2014).

30. Geen, H.; Titman, J. J.; Gottwald, J.; Spiess, H. W. Solid-State Proton Multiple-Quantum NMR Spectroscopy with Fast Magic Angle Spinning. Chem. Phys. Lett. 1994, 227, 79-86.

31. Bendjeriou-Sedjerari, A.; Azzi, J. M.; Abou-Hamad, E.; Anjum, D. H.; Pasha, F. A.; Huang, K.-W.; Emsley, L.; Basset, J.-M. Bipodal Surface Organometallic Complexes with Surface $\mathrm{N}$-Donor Ligands and Application to the Catalytic Cleavage of $\mathrm{C}-\mathrm{H}$ and $\mathrm{C}-\mathrm{C}$ Bonds in $\mathrm{N}-$ Butane. J. Am. Chem. Soc. 2013, 135, 17943-17951.

32. Shao, W. L.; Shinar, J.; Gerstein, B. C.; Li, F.; Lannin, J. S. Magic-Angle Spinning Si ${ }^{29}$ NMR Study of Short-Range Order in a-Si. Phys. Rev. B 1990, 41, 9491-9494.

33. Faulkner, R. A.; DiVerdi, J. A.; Yang, Y.; Kobayashi, T.; Maciel, G. E. The Surface of Nanoparticle Silicon as Studied by Solid-State NMR. Materials 2013, 6, 18-46. 


\section{TABLE OF CONTENTS/ABSTRACT GRAPHIC}

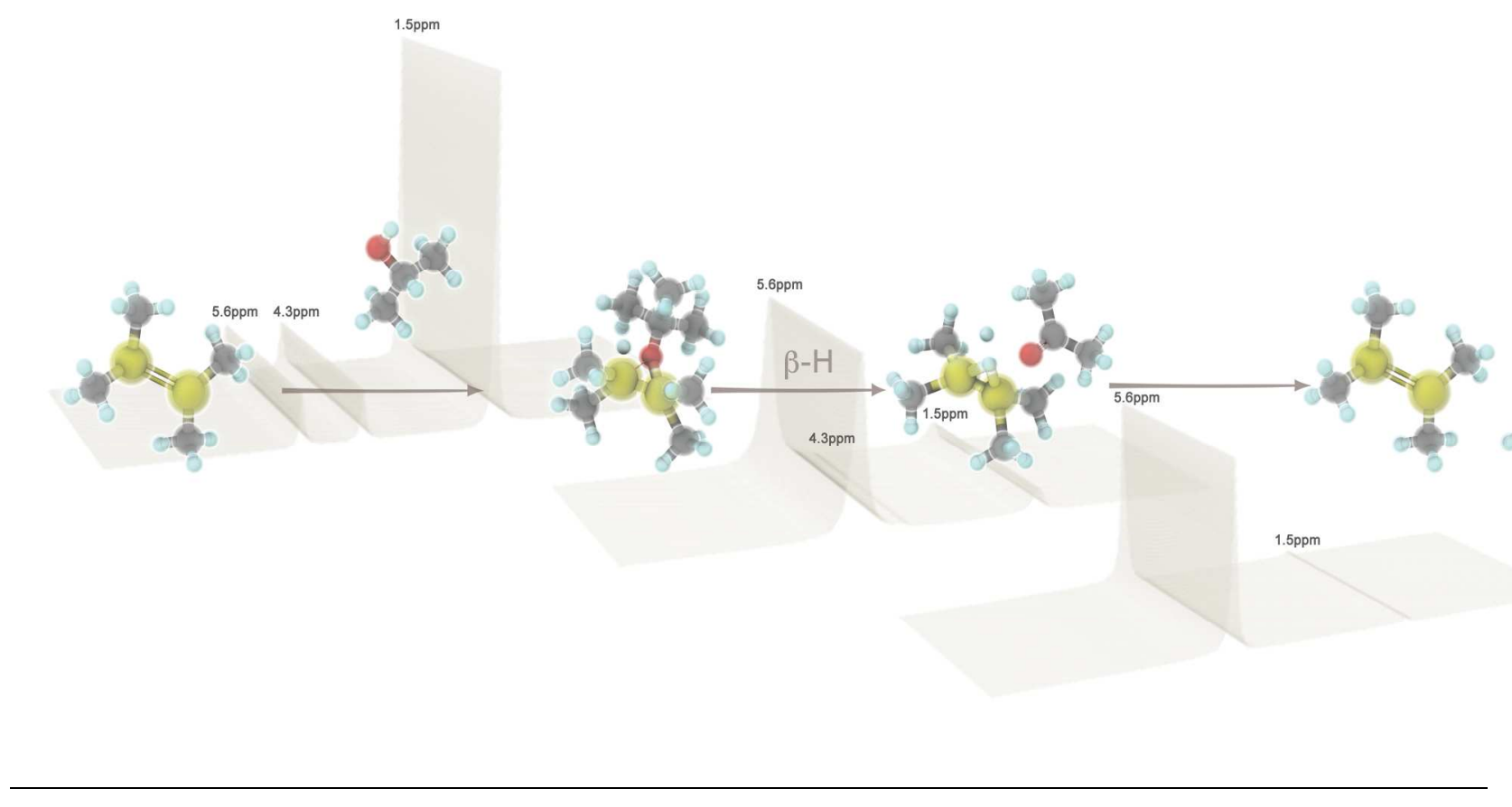

